\title{
XLVI. The position of radium in the periodic system according to its spectrum
}

\section{Runge \&J. Precht}

To cite this article: C. Runge \&J. Precht (1903) XLVI. The position of radium in the periodic system according to its spectrum , Philosophical Magazine Series 6, 5:28, 476-481, DOI: 10.1080/14786440309462945

To link to this article: http://dx.doi.org/10.1080/14786440309462945

曲 Published online: 15 Apr 2009.

Submit your article to this journal $₫$

Џ Article views: 3

Q View related articles $\square$

Citing articles: 1 View citing articles $\square$ 
a spin about the vertical, but also a rolling motion round its axis. (ii.) That even when so spun it is very improbable that its axis would rise to the vertical.

It is found, however, that eggs with their axes horizontal generally do rise to the vertical without any delicate adjustment of their initial spins. We are therefore forced to conclude that this rising is in some way connected with the phenomenon of limiting friction. To test this, an egg was cast in rough cement and spun on a rough stone. It was found that while the smooth wooden eggs rose with great ease, this cement egg only rose with difficulty, and usually remained oscillating between two cones as required by the theory for a "perfectly rough" egg. I hope to deal later with the Problem of Columbus, supposing the egg to be only imperfectly rough; but the analysis promises to be of a much more complex kind.

I have to thank Professor K. Pearson, who first suggested the problem to me, for a great deal of kind assistance and advice during the course of the investigation. I must also thank Mr. W. Arnold Ogden, Demonstrator in the Department of Applied Mathematics, University College, for the trouble and care he took in plotting the curves for the numerical example and in graphically integrating them.

XLVI. The Position of Radium in the Periodic System according to its Spectrum. By C. RUNGe and J. PRECH'T*

7 HE spark-spectrum of radium may be splendidly observed by using the bromide recently prepared by Herr Giesel. A few milligrammes, which Herr Giesel was good enough to place at our disposal for this purpose, enabled us, when using a small amount of dispersion, to produce a decidedly more perfect spectrum than any hitherto observed ; and with greater dispersion, to investigate the lines which are capable of being easily photographed, with respect to their behaviour in a magnetic field. As a result we found that the strongest lines of radium are exactly analogous to the strongest lines of barium and the corresponding lines of the related elements $\mathrm{Mg}, \mathrm{Ca}, \mathrm{Sr}$. As shown by Runge and Paschen $\dagger$, these lines may be grouped into three pairs, called by them, on account

* Translated from the Physikalische Zeitschrift, 4 Jahrgang, no. 10, pp. 285-287.

+ Runge and Paschen, Ber. d. Berl. Akademie, June 26, 1902. 
of certain analogies with the spectra of the alkalies, the linepair of the primary series, the line-pair of the first and that of the secondary series. In the line-pair of the first secondary series there occurs by the side of the line of greater wavelength a feebler line on the side of greater wave-lengths, which Runge and Paschen term a satellite. Measured on the scale of frequency, the two lines of each of the three pairs are the same distance apart for any one element, provided that in the case of the pair of the first secondary series the satellite be taken instead of one of the lines. This distance varies, on the other hand, from one element to another, increasing in a perfectly regular manner with the atomic weight, as will be seen below. In a magnetic field these lines, as has been shown by Runge and Paschen, split up in various ways into components, but in such a manner that, referred to the scale of frequency, the resolution of each line of any one element is precisely the same as that of the corresponding line of each of the other elements.

Now we have found that this also holds for radium, so that $\mathrm{Ra}$ is to be classed along with $\mathrm{Mg}, \mathrm{Ca}, \mathrm{Sr}$, and $\mathrm{Ba}$ in a group of chemically allied elements-a conclusion which is supported by the chemical behaviour of radium, in so far as this is known.

The following table exhibits the correspondence between the lines:-

\begin{tabular}{|c|c|c|c|c|c|}
\hline & Mg. & Ca. & Sr. & Ba. & Ra. \\
\hline Primary Series...... & $\begin{array}{l}2808 \\
2796\end{array}$ & $\begin{array}{l}3969 \\
3934\end{array}$ & $\begin{array}{l}4216 \\
4078\end{array}$ & $\begin{array}{l}4934 \\
4554\end{array}$ & $\begin{array}{l}4682 \\
3815\end{array}$ \\
\hline 1st secondary Series & $\begin{array}{l}\overline{2798} \\
2791\end{array}$ & $\begin{array}{l}3181 \\
3179 \\
3159\end{array}$ & $\begin{array}{l}3475 \\
3465 \\
3381\end{array}$ & $\begin{array}{l}4166 \\
4131 \\
3892\end{array}$ & $\begin{array}{l}\mathbf{4 4 3 6} \\
4341 \\
3650\end{array}$ \\
\hline 2nd $, \quad, \quad\{$ & $\begin{array}{l}2937 \\
2929\end{array}$ & $\begin{array}{l}3737 \\
3706\end{array}$ & $\begin{array}{l}4306 \\
4162\end{array}$ & $\begin{array}{l}4900 \\
4525\end{array}$ & $\begin{array}{l}5814 \\
4533\end{array}$ \\
\hline
\end{tabular}

The resolution of the radium lines in a magnetic field is easily observable with the strongest lines. It is only the resolution of the satellite and of the yellow line 5814 that we have as yet been unable to effect.

For any one element the distances apart of the two lines of each pair are, as already remarked above, equal if measured 
on the scale of frequency. The same holds good for radium, as shown by the following table:-

\begin{tabular}{|c|c|c|c|}
\hline & $\lambda$. & $10^{\varsigma} / \lambda$ & Difference. \\
\hline Primary Series.. & $\begin{array}{r}4682 \cdot 35 \\
3814: 59\end{array}$ & $\begin{array}{l}21356 \cdot 8 \\
26215 \cdot 1\end{array}$ & $4858 \cdot 3$ \\
\hline Ist secondary Series & $\begin{array}{l}4436 \cdot 45 \\
3649 \cdot 77\end{array}$ & $\begin{array}{l}225405 \\
27399 \cdot 0\end{array}$ & $4858 \div 5$ \\
\hline 2 nd $\quad$, & $\begin{array}{l}5813 \cdot 9 \\
4533 \cdot 33\end{array}$ & $\begin{array}{l}17200 \cdot 2 \\
22058 \cdot 8\end{array}$ & $4858 \cdot 6$ \\
\hline
\end{tabular}

The variations in the numbers corresponding to the distances are sufficiently explained by experimental errors. They correspond to very small errors in the wave-length determinations.

From one element to another the distance apart of the lines increases with the atomic weight in the cases of $\mathbf{M g}$, $\mathrm{Ca}, \mathrm{Sr}, \mathrm{Ba}:-$

\begin{tabular}{|c|c|c|}
\hline & Atomic weight. & Distance. \\
\hline $\mathbf{M g} \ldots$ & $24 \cdot 36$ & $91 \cdot 7$ \\
\hline $\mathrm{Ca}$ & $40 \cdot 1$ & 223 \\
\hline $\mathrm{Sr} \quad \ldots$ & $87 \cdot 6$ & 801 \\
\hline $\mathbf{B a} \ldots$ & $137 \cdot 4$ & 1691 \\
\hline
\end{tabular}

It is suggested to regard the atomic weight as a function of the distance between the lines, and to extrapolate this function for radium. It has already been pointed out by Rydberg, Kayser and Runge, in their investigations on the spectrat of the elements, that within a group of chemically related elements the distance apart of the lines of a pair increases regularly with the atomic weight. They state that in the case of alkali metals the atomic weight is very nearly proportional to the square root of this distance. We wish to draw attention to the fact that for the other groups in which line-pairs have been observed, the relation between the width of the line-pairs and the atomic weight is capable of being expressed by a simple formula :-

In each group of chemically related elements the atomic weight varies as some power of the distance apart of the two lines of a par?. 
The exponent is a proper fraction. This result may otherwise be expressed thus :-

The logarithms of the atomic weights and those of the distances when plotted as coordinates lie on a straight line for a chemically related group of elements.

The following two figures illustrate this law.

Fig. 1.

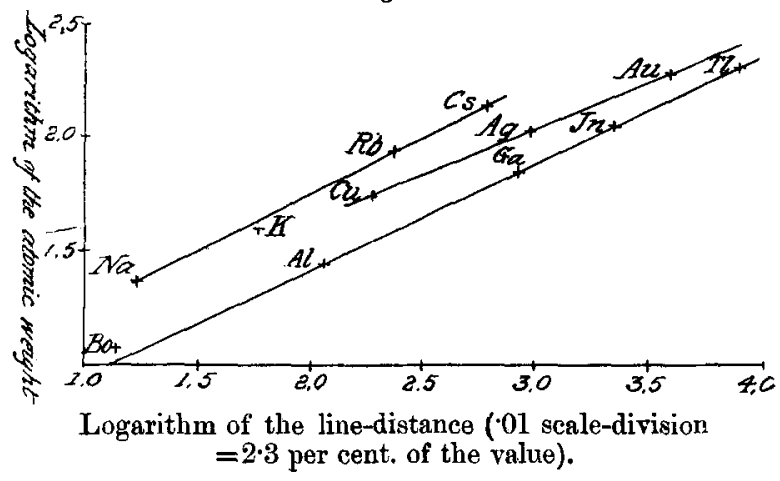

In fig. 1 it will be seen that among the alkalies potassium alone falls slightly below the line passing through the remaining points. We do not mean thereby to suggest that the directly determined atomic weight of potassium is incorrect; but it appears to us interesting that the straight-line law is appreciably departed from precisely in the case of the element whose atomic weight in the periodic system points to an unknown disturbing carse, which produces the inversion of the positions of argon and potassium.

As regards boron, gallium, and indium, the radiation of these elements in a magnetic field has not been investigated. On the other hand, there is no room for doubt as regards the line-pairs corresponding to aluminium and thallium. The same applies to the alkali group, where only the two yellow sodium lines have been investigated in a magnetic field.

In fig. 2 is represented the same relation for $\mathrm{Mg}, \mathrm{Ca}, \mathrm{Sr}$, $\mathrm{Ba}$, and $\mathrm{Ra}$. The extrapolation gives for the atomic weight of radium the value 258. Of course, the straight line may be to some extent rotated and displaced without any great departure from the points; but the figure shows clearly that the value 225 as determined by Madame Curie is considerably removed from the straight line.

In the following table the straight line is represented by a formula, and the extrapolated value obtained by calculation. 
Fig 9.

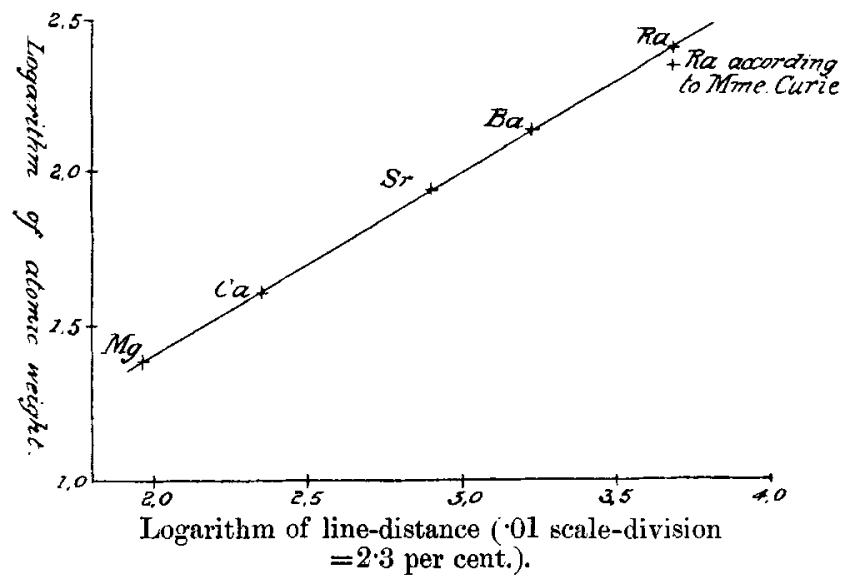

If $x$ stands for the width of the line-pair, measured on the scale of frequency $10^{8} / \lambda$, then we have :-

\begin{tabular}{|c|c|c|}
\hline & $\begin{array}{l}\text { Calculated atomic } \\
\text { weight }=\text { antilog. } \\
(2005+5997 \log x)\end{array}$ & $\begin{array}{c}\text { Observed } \\
\text { atomic weight. }\end{array}$ \\
\hline $\mathrm{Mg} \ldots$ & 2384 & $24 \cdot 36$ \\
\hline $\mathrm{Ca}$ & $40 \cdot 6$ & $40 \cdot 1$ \\
\hline Sr $\ldots$ & $87 \cdot 5$ & $87 \cdot 6$ \\
\hline $\mathrm{Ba} \ldots$ & $136 \cdot 9$ & 137.4 \\
\hline
\end{tabular}

The extrapolation for radium gives for its calculated atomic weight the value $257 \cdot 8$.

We do not venture to suppose that our value deserves more confidence than that determined by Mme. Curie. It must, however, be remarked that in view of the close relationship of barium and radium, and the small quantities with which the chemist is forced to work, the complete separation of these two bodies is very difficult, and that if the separation had been incomplete Mme. Curie would have found too small a value for the atomic weight. According to the crystallographic observations of F. Rinne, to be published shortly, radium bromide and barium bromide are isomorphic, so that a joint crystallization of both substances (an somorphic mixture) is, from à priori considerations, highly 
probable-on the assumption of similar solubility relations. From this will be understood the great difficulty of separating these substances by crystallization, so that even after frequently repeated re-crystallizations the corresponding radium compound may contain more or less barium. The same holds for the relation of radium to calcium as well as to strontium and magnesium.

The number 225 is in better correspondence with the periodic system, in so far as it fits the gap between bismuth and thorium in the proper column. According to the value 258 , radium would have to be moved two rows further down in the column $\mathrm{Mg}, \mathrm{Ca}, \mathrm{Sr}, \mathrm{Ba}$, and a number of new unoccupied places would be created in the periodic system.

On the other hand, Rutherford's remark may be adduced in support of the higher value of the atomic weight. The higher atomic weight is indicative of a more complicated atomic structure, and therefore of an easier splitting up into electrons. The element which gives off electrons most freely should therefore also have the highest atomic weight.

The radium line $482 b^{\circ} \cdot 14$, which is the most prominent of all in a Bunsen-flame, is also after resolution in a magnetic field found to be analogous to the strongest Bunsen-flame lines $\mathrm{Ba} 5535, \mathrm{Sr} 4607, \mathrm{Ca} 4226$. All these lines become resolved into triplets, which in the case of the elements considered consist of equidistant lines, the frequency scale being: used.

Hanover, Physical Institute of the Technical High School. January 1903.

XLVII. Some Remarks on Radioactivity.

To the Editors of the Philosophical Magazine. Gentlemen,

IN a recent number of the Comptes Rendus, Jan. 26, 1903, 1 there appeared a paper by M. Henri Becquerel, entitled "Sur la déviabilité magnétique et la nature des certains rayons émis par le radium et le polonium," and also one by M. P. Curie "Sur la radioactivité induite et sur l'émanation du radium," in the former of which certain criticisms of my experimental methods, and in the latter of my theoretical views were made.

I am very pleased that M. Becquerel, with the very active material at his disposal, has confirmed in such a direct manner by the photographic method the results which I had previously obtained by the electric method*, showing

* Phys. Zeit. No. 8, p. 235, Jan. 15 (1903); Phil. Mag. Feb. 1903. 